\title{
Coupling Simulation Analysis on Support System of High-energy Storage Flywheel System
}

\author{
Wang Wan \\ School of Mechanical engineering, Guizhou University, China \\ National Engineering Research Center for Small and Special \\ precision Motor, China \\ wangwan81@126.com
}

\begin{abstract}
A 3D model of the upper and lower support were established via ANSYS WORKBENCH14 on the basis of a new cooling system and both temperature and stress of different materials coupling simulation analysis have been done. The result shows that: One of the best choices of the material of the supports were copper alloy, which has a little impact on the thermal stress of the whole system. The heat generated from the bearing and motor can be removed by using the proposed cooling system timely so that the temperature of the flywheel system can be maintained in a normal range.
\end{abstract}

\section{Keywords-High-energy storage flywheel system; Support}

\section{system; Coupling simulation}

As the high-energy storage flywheel system produces heat loss in the precedure of store-release energy, the design of the cooling system becomes one of the key techniques in the engineering application of the high energy storage flywheel system. Common cooling model nowadays includes circulating water cooling system, air cooling system, and heat sink cooling system, etc [1]. Although circulating water cooling system performs better than air cooling system, its equipment has many defects, such as the complexity and leakiness, which make it very difficult to manage. Moreover, convection in vacuum is negligible. The cooling effect can be achieved effectively by using conduction.

\section{THE DESIGN OF COOLING SYSTEM}

Taking into account safety issue, the high-energy storage flywheel system is usually set in underground. The performance of cooling system depends on thermal conductivity of the soil, which is closely linked with the heating part, while, the thermal conductivity of the soil is very poor.

The heat through the support with high heat conduction performance will transfer to the cylinder body of the vacuum chamber, and finally achieve the ground via the cylinder which is coupled with the high-performance components. Fins are added at the part on the ground to ensure that temperature of the support system is stable. The structure of cooling system is shown in Fig. 1.

\author{
He Lin \\ School of Mechanical engineering, Guizhou University, China \\ National Engineering Research Center for Small and Special \\ precision Motor, China \\ helin6568@163.com
}

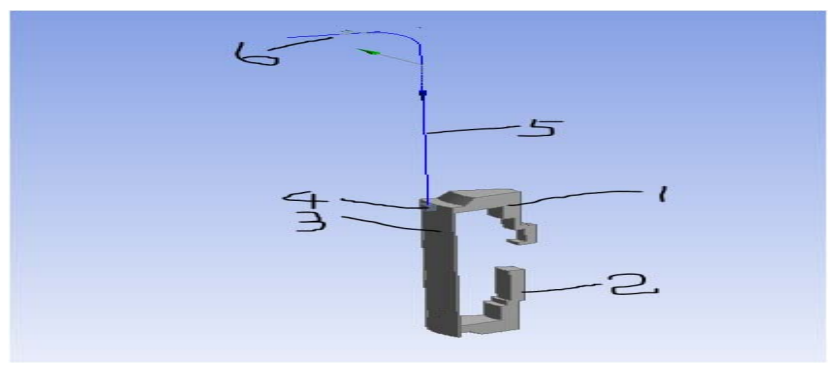

Fig. 1 Structure of cooling system

$$
\begin{array}{ll}
\text { 1.upper support; } & \text { 2.lower support; } \\
\text { 3.the cylinder body; } & \text { 4.thermal coupling element; } \\
\text { 5.high-performance components ; } & 6 . \text { fin } \\
\text { II } \quad \text { THE SIMULATION AND ANALYSIS OF COOLING } \\
\text { COMPONENTS }
\end{array}
$$

\section{THE SIMULATION AND ANALYSIS OF COOLING}

The sources of heat production for the high-energy storage flywheel system are 1 , the friction of mechanical bearing; 2 , the coil of electromagnetic bearing; 3 , the iron loss and copper loss of permanent magnet brushless motor. The position of the parts are on the upper and lower support. Due to the actual situation, the coupling simulation analysis on both temperature and stress of different materials were doing respectively.

It is hard to obtain the results through the analytic way for this kind of coupling problem, so numerical calculation way, by using the convection - conduction coupled simplified mode, should be used to accomplish this problem.

\section{A Hypothesis}

These hypothesis have been used through the process as follows, (1) ignore the thermal contact resistance; (2)ignore the radiation and convection of the internal surface; (3)the air is constant property; (4) the high performance heat conduction component is equivalent to the same geometric size metal rod with excellent thermal conductive performance. Based on the classic theory such as the principle of conservation of energy, the Fourier law, Newton cooling formula, the finite element analysis software was used during the process of this analysis. 
$B$ The finite element method and the solution of governing equation

Based on the classic theory[3] such as the principle of conservation of energy, the Fourier law, Newton cooling formula, the governing equation of heat transfer problem was deduced as follows

$\frac{\partial}{\partial x}\left(k_{x} \frac{\partial T}{\partial x}\right)+\frac{\partial}{\partial y}\left(k_{y} \frac{\partial T}{\partial y}\right)+\frac{\partial}{\partial z}\left(k_{z} \frac{\partial T}{\partial z}\right)+\rho Q=\rho c_{T} \frac{\partial T}{\partial t}$

the instantaneous temperature field in the object $T(x, y, z, t)$ satisfied the governing equation, which $\rho$ is $\mathrm{kg}$

the density of material, $\left(/ \mathrm{m}^{3}\right) ; C_{T}$ was specific heat $J /(k g \cdot K)) ; k_{x} 、 k_{y}, k_{z}$ is the heat conduction coefficient along the direction $\mathrm{x}, \mathrm{y}, \mathrm{z}$, respectively $W /(m \cdot K)) Q(x, y, z, t)$ $\mathrm{W} / \mathrm{kg}$ is heat-intensity in the object ) Heat transfer boundary conditions was: Given the distribution of temperature $T(x, y, z, t)=\bar{T}(t) \quad S_{1}$; Given the heat flow $k_{x} \frac{\partial T}{\partial x} n_{x}+k_{y} \frac{\partial T}{\partial y} n_{y}+k_{z} \frac{\partial T}{\partial z} n_{z}=q_{f}(t)$

$S_{2}$;Given the convective heat transfer coefficients to surroundings

$k_{x} \frac{\partial T}{\partial x} n_{x}+k_{y} \frac{\partial T}{\partial y} n_{y}+k_{z} \frac{\partial T}{\partial z} n_{z}=h_{c}\left(T_{\infty}-T\right)$ at $S_{3} ;$

where $n_{x}, n_{y}, n_{z}$ are the direction cosine of outer normal vector at boundary; $\bar{T}(t)$ is the given temperature at boundary $S_{1} ; \bar{q}_{f}(t)$ is the heat flow at boundary $S_{2}$ $\left(W / m^{2}\right), h_{c}$ is the convective heat transfer coefficients to surroundings at boundary $S_{3} \mathrm{~W} /\left(\mathrm{m}^{2} \cdot K\right), T_{\infty}$ is ambient temperature $(K)$; the boundary of the subject is $\Omega$, and $\partial \Omega=S_{1}+S_{2}+S_{3}$.

Initial condition is $T(x, y, z, t=0)=\bar{T}_{o}(x, y, z)$, then the solving problem of heat transfer can be transformed to an functional extreme value problem .

\section{Simulation}

In order to ensure the correctness of the simulation, reduce the cost and improve the precision of the calculation, $30^{\circ} 3 \mathrm{D}$ models of upper and lower support were taken in the ANSYS WORKBENCH14 DESIGN MODER in this paper. Specific steps [4]were as follows: 1, call engineering data; 2, add materials; 3, tune in the steady state thermal analysis; 4, import Material data into steady state analysis; 5, import geometric model; 6,steady state thermal analysis; 7, transfer the results of steady state thermal analysis into transient thermal analysis; 8 , instant thermal analysis.

\section{RESULTS AND DISCUSSION}

A The analysis of the highest temperature of supports of different material properties with the boundary of different temperature.

\section{1 ) Upper support}

The heat-conducting property of upper support changed with different material, the temperature of the steady state differed with material properties. The maximum difference of temperature rise was $149.4^{\circ} \mathrm{C}$. The steady temperature of the copper alloy was the lowest, $58.6{ }^{\circ} \mathrm{C}$; the steady temperature of the titanium alloy was the highest, $207.9{ }^{\circ} \mathrm{C}$. Titanium alloy is not suitable for manufacturing support. Table 1 was the highest temperature of the upper support of different material properties with the boundary of different temperature, it can be demonstrated that the temperature boundary effect is great on the final temperature. The temperature boundary would be strictly controlled to ensure the normal temperature range of the support.

TABLE 1 THE HIGHEST TEMPERATURE OF THE UPPER SUPPORT OF DIFFERENT MATERIAL PROPERTIES WITH THE BOUNDARY OF DIFFERENT TEMPERATURE

\begin{tabular}{|c|c|c|c|c|c|}
\hline & $\begin{array}{c}\text { temperature boundary } \\
\left({ }^{\circ} \mathrm{C}\right)\end{array}$ & alumium alloy & copper alloy & structure steel & titanium alloy \\
\hline $\mathrm{T}_{\max }\left({ }^{\circ} \mathrm{C}\right)$ & 50 & 72.2 & 58.6 & 107.2 & 207.9 \\
\hline $\mathrm{T}_{\max }\left({ }^{\circ} \mathrm{C}\right)$ & 22 & 45.1 & 30.6 & 79.2 & 180.0 \\
\hline
\end{tabular}

\section{2) Lower support}

Table 2 is the highest temperature of the lower support of different material properties. the maximum difference of temperature rise is $171.4^{\circ} \mathrm{C}$. The steady temperature of the copper alloy is the lowest $51{ }^{\circ} \mathrm{C}$; the steady temperature of the titanium alloy is the highest $222.4^{\circ} \mathrm{C}$. 
TABLE 2 THE HIGHEST TEMPERATURE OF THE LOWER SUPPORT OF DIFFERENT MATERIAL PROPERTIES

\begin{tabular}{|c|c|c|c|c|c|}
\hline & $\begin{array}{c}\text { temperature } \\
\text { boundary }\left({ }^{\circ} \mathrm{C}\right)\end{array}$ & alumium alloy & copper alloy & structure steel & titanium alloy \\
\hline $\mathrm{T}_{\max }(\mathrm{\circ} \mathrm{C})$ & 22 & 51.0 & 32.9 & 94.5 & 222.4 \\
\hline
\end{tabular}

$B \quad$ The analysis of the deformation and equivalent stress of supports of different material properties with the boundary of different load.

\section{1) Upper support}

The upper support is working under the gravity of the entire wheel and the thermal stress. Table 3 is the deformation of the end face and equivalent stress of upper supports with different load. From table 3, it is shown that the deformation of the end face was $0.1 \mathrm{~mm}$ order of magnitude, regardless of the load is $15000 \mathrm{~N}$ or $20000 \mathrm{~N}$. So the deformation do nothing to the normal operation of the whole system; the highest equivalent stress is $34.5 \mathrm{Mpa}$, which is far less than the ultimate strength of materials, the strength index of the support fullfill the design requirements.

TABLE 3 THE DEFORMATION AND EQUIVALENT STRESS OF THE END FACE OF UPPER SUPPORT WITH DIFFERENT LOAD

\begin{tabular}{|c|c|c|c|c|c|}
\hline & load & alumium alloy & copper alloy & structure steel & titanium alloy \\
\hline $\mathrm{X}_{\max }(\mathrm{m})$ & \multirow{2}{*}{$15000 \mathrm{~N}$} & $5.93 \mathrm{e}-4$ & $3.81 \mathrm{e}-4$ & $2.12 \mathrm{e}-4$ & $4.34 \mathrm{e}-4$ \\
\hline $\mathrm{X}_{\min }(\mathrm{m})$ & & $3.06 \mathrm{e}-4$ & $1.97 \mathrm{e}-4$ & $1.09 \mathrm{e}-4$ & $2.24 \mathrm{e}-4$ \\
\hline $\mathrm{F}_{\mathrm{eq}}(\mathrm{pa})$ & \multicolumn{5}{|c|}{$3.44 \mathrm{e} 7$} \\
\hline $\mathrm{X}_{\max }(\mathrm{m})$ & \multirow{2}{*}{$20000 \mathrm{~N}$} & $7.90 \mathrm{e}-4$ & $5.08 \mathrm{e}-4$ & $2.83 e-4$ & $5.78 \mathrm{e}-4$ \\
\hline $\mathrm{X}_{\min }(\mathrm{m})$ & & $4.09 \mathrm{e}-4$ & $2.62 \mathrm{e}-4$ & $1.46 \mathrm{e}-4$ & $2.98 \mathrm{e}-4$ \\
\hline $\mathrm{F}_{\mathrm{eq}}(\mathrm{pa})$ & \multicolumn{5}{|c|}{$4.58 \mathrm{e} 7$} \\
\hline
\end{tabular}

\section{CONCLUSION}

The high-energy storage flywheel system should maintain the normal temperature by using the designed cooling system. The temperature rise and thermal stress of supports varied with different materials greatly. The temperature rise can be effectively reduced by reasonable choice of support material. One of the best choices of the material of the supports is copper alloy, which have a little impact on the thermal stress of the whole system.

In the proposed design condition with the coupling of the thermal stress and external load, the supports' strength and the deformation of the end face fullfill the design requirements.

\section{EFERENCES}

[1] DaiXingJian, TangChangLiang, ZhangKai: The Research Progresses of the Advanced Energy-Storage Flywheel for Power Engineering Application, power technology, Vol. 33 (2009), pp. 1026-1029.

[2] F.P. pilates because crowe, D.P. Dwight.Basis of Heat Transfer(Trans Tech Publications, China 1987).tianjin

[3] finite element method in engineering, zengpan, shiwei,leiliping Science Press2010The First Edition

[4] ANSYS 13.0WORKBENCH numerical simulation technology .xujingjing.China WaterPower Press2012The First Edition Beijing 